\title{
DISSEMINAÇÃO DE INFORMAÇÕES PREVENTIVAS SOBRE INTOXICAÇÕES EXÓGENAS EM TEMPOS DE COVID-I9:
}

\section{relato de experiência}

\section{Dannielly Azevedo de Oliveira ${ }^{1}$ \\ Jayara Mikarla de Lira ${ }^{2}$ \\ Ayrlla Vytória Pereira ${ }^{3}$ \\ Kaio Dênnys de Lucena Martins ${ }^{4}$ \\ Astha Oliveira Catônio de Araújo ${ }^{5}$}

\section{RESUMO}

$\mathrm{T}$ rata-se de um estudo descritivo, do tipo relato de experiência, vinculado ao projeto de extensão "Formação de Multiplicadores de Informações Preventivas sobre Intoxicações Exógenas", realizado por alunos de graduação do Curso de Enfermagem da Faculdade de Ciências de Saúde do Trairi (FACISA/UFRN), campus Santa Cruz/RN, ocorrido de abril a setembro de 2020. O objetivo desse estudo é relatar a experiência do desenvolvimento de material informativo para orientação da população em geral sobre os riscos de acidentes envolvendo intoxicações exógenas. Apesar do distanciamento social, decorrente da pandemia da COVID-I9, o projeto conseguiu efetivar seu propósito a partir da criação de materiais informativos do tipo cartilhas e manuais para disseminar conhecimento por meio das redes sociais, apresentando grande significância no que visa a contribuir para uma melhoria na qualidade de vida da população.

Palavras-chave: Toxicologia; Educação em saúde; Isolamento social; Mídias Sociais.

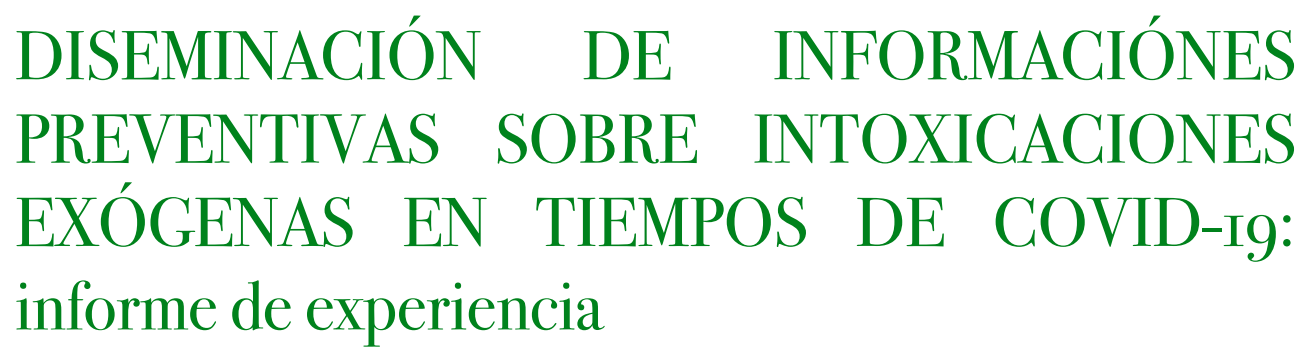

\section{RESUMEN}

Se trata de un estudio descriptivo, tipo informe de experiencia, vinculado al Nproyecto de extensión "Capacitación de Multiplicadores de Información Preventiva sobre Intoxicaciones Exógenas", realizado por estudiantes de pregrado de Enfermería de la Faculdade de Ciências de Saúde do Trairi (FACISÁ / UFRN), campus Santa Cruz/RN, realizado em el periodo de abril a septiembre de 2020. El objetivo de este estudio es relatar la experiencia del desarrollo material informativo para la orientación de la población en general sobre los riesgos de accidentes evolviendo intoxicaciones exógenas. A pesar del distanciamiento social, resultante de la pandemia COVID-I9, el proyecto logró llevar a cabo su propósito mediante la creación de materiales informativos del tipo folletos y manuales para diseminarr conocimiento a través de los medios de comunicación sociales, apresentando gran importancia en fines de contribuir a una mejora en la calidad de vida de la población.

Palabras clave: Toxicología; Educación em salud; Aislamiento social; Medios de comunicación sociales.
1 Doutoranda em Saúde coletiva pelo Programa de Pós-graduação em Saúde Coletiva da UFRN . Docente do Curso de Enfermagem. Mestre em Saúde coletiva pelo Programa de Pós-graduação em Saúde Coletiva da UFRN. Instituição: Universidade Federal do Rio Grande do Norte/Faculdade de ciências da Saúde do Trairi - UFRN/FACISA

2 Discente do curso de Enfermagem. Instituicão: Universidade Federal do Rio Grande do Norte/Faculdade de Ciências da Saúde do Trairi - UFRN/FACISA

${ }^{3}$ Discente do curso de Enfermagem. Instituição: Universidade Federal do Rio Grande do Norte/Faculdade de Ciências da Saúde do Trairi - UFRN/FACISA

${ }^{4}$ Discente do curso de Enfermagem. Instituição: Universidade Federal do Rio Grande do Norte/Faculdade de Ciências da Saúde do Trairi - UFRN/FACISA

${ }^{5}$ Discente do curso de Enfermagem. Instituição: Universidade Federal do Rio Grande do Norte/Faculdade de Ciências da Saúde do Trairi - UFRN/FACISA 


\title{
DISSEMINATION OF PREVENTIVE INFORMATION ABOUT EXOGENOUS POISONINGINTIMESOFCOVID-I9: experience
}

\author{
report
}

\begin{abstract}
This is a descriptive study, of the experienced report, linked to an extension project called "Training of Preventive Information Multipliers on Exogenous Poisoning", done by undergraduated nursing students of the "Faculty of Health Sciences of Trairi" (FACISA/UFRN), Santa Cruz/RN campus, took place from April to September 202O. The purpose of this study is reporting the experience of developing informative materials to guide general population about the accident risks involving exogenous poisoning. Despite the social distancing, caused by the COVID-I9 pandemic, the project was successful in its purpose, by creating materials like booklets and manuals to disseminate knowledge through social media, showing large significance in what it aims, which is to improve the quality of life of the population.
\end{abstract}

Keywords: Toxicology; Health education; Social isolation; Social media.

\section{INTRODUÇÃO}

Com o advento da tecnologia, o estilo de vida das pessoas foi se modificando Cao longo tempo e , hodiernamente, é perceptível que esses indivíduos passam mais tempo fora de casa, seja em decorrência de trabalho ou estudo, o que implica uma rotina intensa e cansativa, facilitando que quadros de intoxicações exógenas possam ocorrer por falta de atenção. Um estudo realizado por Bortoletto e Bochner (I999), mostrou que grande parte das intoxicações são acidentais e, portanto, evitáveis. Atrelado a isso, houve uma excessiva migração do campo para a cidade, o que resultou em um processo de urbanização. Por sua vez, "a urbanização, por implicar na concentração de pessoas e atividades produtivas sobre um espaço restrito, gera, necessariamente, impactos degradadores do meio ambiente com efeitos sinérgicos e persistentes"(JATOBÁ, 2OII, p. I4I)

Diante do exposto, vêm à tona questões importantes: essa degradação do meio ambiente pode ocasionar a destruição de habitats de alguns animais, entre eles, animais peçonhentos, e por consequência, isso pode motivar acidentes envolvendo esses bichos. E tendo em vista o novo contexto causado pela pandemia da COVID-I9, as pessoas passaram a viver mais tempo em seus domicílios, seguindo as recomendações das autoridades sanitárias de isolamento e de distanciamento social, como forma de retardar a velocidade de expansão do novo Coronavírus. Com o favorecimento da intensificação do convívio familiar, aumentaram os riscos para ocorrências de acidentes toxicológicos nesses ambientes, tanto urbanos quanto rurais.

As crianças, em especial, merecem atenção redobrada nesse momento, pois estando sem frequentar a escola, sem brincar com seus colegas ou sem sair para passear, acabam por gerar um acúmulo de energia e tendem a procurar dentro do lar formas de se divertir devido a sua curiosidade nata, o que pode representar um perigo, pois, "o ambiente doméstico é o lugar em que ocorrem os acidentes mais frequentes nos primeiros anos de vida” (VILAÇA; CARDOSO, 2OI4, p. 22).

Outra questão é que o cultivo de plantas em domicílios se mostrou como uma alternativa de enfrentamento ao isolamento social. Diante disso, é necessário infor- 
mar à população que as plantas produzem uma diversidade de substâncias químicas capazes de gerar intoxicações (CAMPOS et al., 20I6).

De forma geral, são muitas as substâncias capazes de gerar intoxicações em seres humanos, entre elas, foram destacadas nas capacitações do curso: intoxicações por medicamentos, por animais peçonhentos, por plantas tóxicas e por domissanitários. Além das questões já citadas, os casos de intoxicações resultam significativamente em despesas com cuidados de saúde, histórico de morbidade agregada e mortalidade (GARCIA; POLISEL; FRANCK, 2OI7). Diante disso, faz-se necessário debater sobre essa temática nos diferentes âmbitos da sociedade, visando à prevenção de acidentes. Assim, surgiu o curso de extensão intitulado "Formação de Multiplicadores de Informações Preventivas sobre Intoxicações Exógenas", cuja finalidade consiste em promover a capacitação e a qualificação dos profissionais de saúde (atenção básica) e da área da educação (professores) no município de Santa Cruz, Rio Grande do Norte.

Antes das ações desenvolvidas, foram realizadas capacitações entre os membros integrantes do projeto de extensão (discentes, docentes e técnicos administrativos da área da saúde) para que todos pudessem se apropriar dos conhecimentos sobre a área da toxicologia. As capacitações foram adaptadas para o modo virtual, em decorrência das medidas de distanciamento social adotadas no contexto da pandemia provocada pelo novo coronavírus, conhecido como SARS-CoV-2 (Severe Acute Respiratory Syndrome), causador da doença por coronavírus 20I9 (COVID-I9).

Inicialmente, foi recomendado pela coordenadora do curso de extensão que todos os integrantes realizassem o curso online de educação a distância sobre Acidentes Tóxicos com Animais Peçonhentos, ofertado de forma gratuita, pelo Centro de Informação Toxicológica do Rio Grande do Sul em parceria com o Núcleo de Telessaúde da Universidade Federal do Rio Grande do Sul, com carga horária de 30 horas.

Além disso, outros temas da área de toxicologia foram discutidos e apresentados entre o grupo na forma de seminários. Sem a possibilidade de encontros presenciais, foram realizadas diversas reuniões online com o objetivo de debater temáticas, previamente estabelecidas entre o grupo, e organizar materiais informativos para divulgação à população geral.

Foi observado que a sociedade, de maneira geral, carece de informações sobre intoxicações exógenas, pois muitas vezes não sabem como proceder diante de um acidente que, a depender de uma série de fatores, pode colocar em risco a vida de um ou mais indivíduos. Nesse sentido, o curso de extensão torna-se necessário e importante na medida em que busca fornecer informações sobre as diversas características relacionadas à intoxicação, mal que continua como um sério problema de saúde pública em nível mundial, apesar dos esforços governamentais em combatê-lo.

Nesse contexto, as ações educativas do curso de extensão foram direcionadas para esse público, fornecendo orientações para as pessoas sobre como prevenir e o que fazer diante da intoxicação exógena por medicamento, da intoxicação exógena por domissanitários, da intoxicação exógena por plantas tóxicas e dos acidentes com animais peçonhentos. Sobre esse último, vale destacar que embora existam numerosos estudos sobre os animais peçonhentos, o que se verifica no Brasil é que eles ainda são pouco conhecidos (MONACO; MEIRELES; ABDULLATIF, 2OI7).

Este estudo tem como objetivo relatar a experiência do desenvolvimento de material informativo para orientação da população em geral sobre os riscos de acidentes envolvendo intoxicações exógenas. 


\section{METODOLOGIA}

Trata-se de um estudo descritivo, do tipo relato de experiência, vinculado ao curso de extensão "Formação de Multiplicadores de Informações Preventivas sobre Intoxicações Exógenas", realizado por alunos de graduação do Curso de Enfermagem da FACISA/UFRN, no município de Santa Cruz, Rio Grande do Norte, coordenado por docente e servidores da FACISA.

O projeto foi criado no início de $202 \mathrm{O}$, com intuito de capacitar e qualificar profissionais da área da saúde, em especial os agentes comunitários de saúde, e profissionais da área da educação (professores) do município de Santa Cruz, Rio Grande do Norte, para identificar os principais agentes intoxicantes e animais peçonhentos, e compreender o manejo dos primeiros socorros diante dos quadros de intoxicação exógena, tornando-os agentes multiplicadores de informações preventivas.

Esse projeto está sendo desenvolvido sob a coordenação de uma docente do Curso de Enfermagem da Faculdade de Ciências da Saúde do Trairi (FACISA), juntamente a três Enfermeiros servidores desta instituição, a qual consiste em uma unidade especializada da Universidade Federal do Rio Grande do Norte (UFRN), onde são ofertados os cursos de graduação em Enfermagem, Fisioterapia, Nutrição e Psicologia. Esse grupo coordena e direciona as atividades para que se cumpra o objetivo e se alcance os resultados esperados, tendo a participação de quatro discentes do curso de enfermagem, de períodos letivos variados.

Diante da situação da pandemia da COVID-I9 e da consequente paralisação das atividades presenciais nas instituições de educação, entre elas a UFRN, foi necessário adaptar a metodologia do curso de extensão, voltado, a princípio, para a realização de encontros presenciais com os profissionais da saúde e da educação, conforme mencionado anteriormente. Desse modo, as ações do curso foram direcionadas ao objetivo de sensibilizar a população em geral sobre os riscos de acidentes envolvendo intoxicações exógenas, de forma remota, utilizando-se da tecnologia para atingir o objetivo estabelecido, tendo sido realizado de abril a setembro de $2 \mathrm{O} 2 \mathrm{O}$.

Para isso, foram usadas diferentes plataformas online para o desenvolvimento das atividades. As reuniões para planejamento das açõe s e apresentação dos seminários foram realizadas na plataforma do Google Meet. O aplicativo WhatsApp foi utilizado para a criação de um grupo com todos os integrantes do curso de extensão para planejar a continuidade das ações, para o compartilhamento de materiais e para o esclarecimento de dúvidas. Os materiais informativos, produzidos pelos integrantes, com orientações sobre intoxicações exógenas foram divulgados para a população por meio da rede social Instagram.

Durante os primeiros encontros de forma remota, decidiu-se pela realização de um curso online sobre animais venenosos e peçonhentos, sendo este, a principal base para a primeira cartilha informativa, além da leitura de diversos artigos científicos sobre demais temas relacionados à área da toxicologia. Para a elaboração do material sobre acidentes com animais peçonhentos, utilizou-se a plataforma de design gráfico Canva.

Ressalta-se que a incidência de acidentes provocados por animais peçonhentos vem aumentando ao longo dos anos (BRASIL, 2OI9). Assim, as cartilhas educativas abordaram os principais animais peçonhentos encontrados nos domicílios urbanos, quais sejam: escorpiões e aranha marrom. Essas cartilhas trataram das características desses animais; ocorrência de acidentes; principais sinais e sintomas; primeiros socorros; tratamento e medidas de prevenção.

Os materiais foram veiculados pelo Instagram através da página @ufrnfacisa, e da página @coronavirusdiariorn, além do compartilhamento via multiplataforma 
WhatsApp. A escolha dessas redes sociais aconteceu pela possibilidade de um maior alcance de pessoas e pela diversidade de público. A opção favoreceu o compartilhamento das informações para muitas pessoas, dada a relevância da temática apresentada.

Após a primeira ação realizada, e almejando elevar os conhecimentos dos participantes acerca dos demais temas discutidos na área da toxicologia, houve a divisão dos integrantes em duplas para a realização de seminários, possibilitando uma dinâmica e troca mútua de conhecimentos. Para a construção dos seminários, foi realizada uma busca nas bases de dados MedLine, LILACS, SciELO, PubMed e Google Acadêmico para levantamento de material científico sobre os temas.

Os seminários foram apresentados por meio de slides elaborados no programa Microsoft PowerPoint, os quais foram expostos por cada dupla aos demais integrantes pelo Google Meet. Além disso, houve também a elaboração de manuais relacionados às temáticas, produtos dos seminários, sobre intoxicação exógena por animais peçonhentos, por plantas tóxicas, por medicamentos e por domissanitários, os quais estão sendo catalogados para, posteriormente, serem compartilhados e disponibilizados para a população.

\section{RESULTADOS}

$\mathrm{O}$ contexto em que vivemos no ano de 2020 , impossibilitou a realização da metodologia formulada pelos idealizadores do projeto. Apesar disso, os resultados que foram almejados permaneceram os mesmos, corroborados ainda mais pelo fato de que a população, com a quarentena e distanciamento social, passa mais tempo em casa, podendo haver riscos de intoxicação por animais peçonhentos, plantas tóxicas, uso inadequado de medicamentos e até mesmo por domissanitários, sendo as crianças os principais em risco, segundo os dados disponibilizados pelo Sistema Nacional de Informações Tóxico-Farmacológicas (BRASIL, 2OI7). Desse modo, apesar de ter sido necessário efetivar modificações nas atividades realizadas, os resultados apreciados mantiveram-se.

A Carta de Ottawa de I986 reafirma a importância da promoção à saúde e aponta como o processo de capacitação da comunidade é capaz de atuar na melhoria de sua qualidade de vida e saúde, incluindo uma maior participação no controle deste processo (HEIDMANN et al., 2006). Desse modo, o principal propósito do projeto de extensão, disseminar informações sobre intoxicações exógenas para a população, foi efetivado a partir da criação de materiais informativos, que discorrem sobre a temática da área de toxicologia de maneira simples e de fácil entendimento para população leiga. Em virtude do uso da internet e das redes sociais, obtivemos como resultado uma maior e mais rápida difusão das cartilhas informativas elaboradas pelos integrantes do projeto (figuras I e 2).

Assim, se inicialmente, as ações estavam voltadas para o município de Santa Cruz, com o formato remoto foi possível expandir o alcance do conhecimento para além dos limites do território em que se encontra a universidade, permitindo que mais pessoas tivessem acesso a informações sobre os temas abordados no curso, colaborando para a adoção e disseminação de medidas de prevenção adequadas nos casos de intoxicações exógenas, a fim de diminuir suas ocorrências.

Ademais, tanto para a elaboração das cartilhas, quanto para os momentos de capacitação entre os integrantes, foi oportunizado o desenvolvimento de competências e aquisição de novos conhecimentos sobre as intoxicações exógenas, com a realização de pesquisas bibliográficas sobre os temas para apresentação dos seminários pelos integrantes e a realização do Curso EAD de Acidentes Tóxicos por Animais Peçonhentos $6^{\circ}$ Edição do Moodle TelessaúdeRS-UFRGS. A ampliação do conhecimento e a troca de saberes sobre temas relacionados às intoxicações exógenas possui ampla importância, pois são temas pouco difundidos nos cursos de formação na área da saúde. 
A experiência também oportunizou o desenvolvimento de habilidades com ferramentas tecnológicas, como o Canva, que proporcionou a criação de folders e materiais educativos para propagação nos meios digitais, em especial nas redes sociais. Além disso, devido ao contexto de pandemia, os encontros de orientações ocorreram por meio do Google Meet.

Figura I: Capa da cartilha sobre os acidentes com aranha marrom, vinculada ao projeto "Formação de Multiplicadores de Informações Preventivas sobre Intoxicações Exógenas"

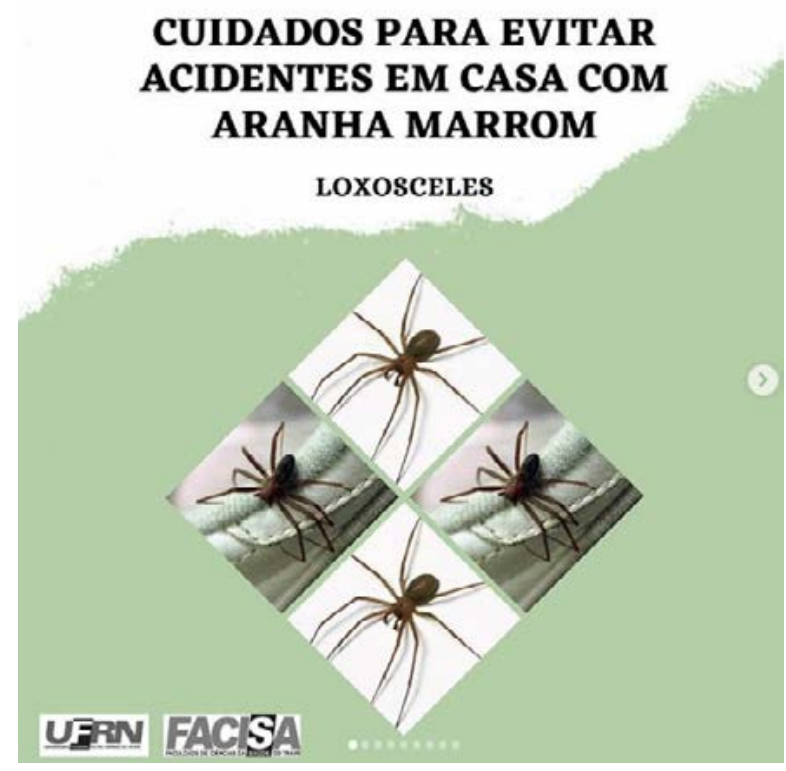

Fonte: Oliveira et al., 2020 .

Figura 2: Capa da cartilha sobre os acidentes com escorpiões, vinculada ao projeto "Formação de Multiplicadores de Informações Preventivas sobre Intoxicações Exógenas"

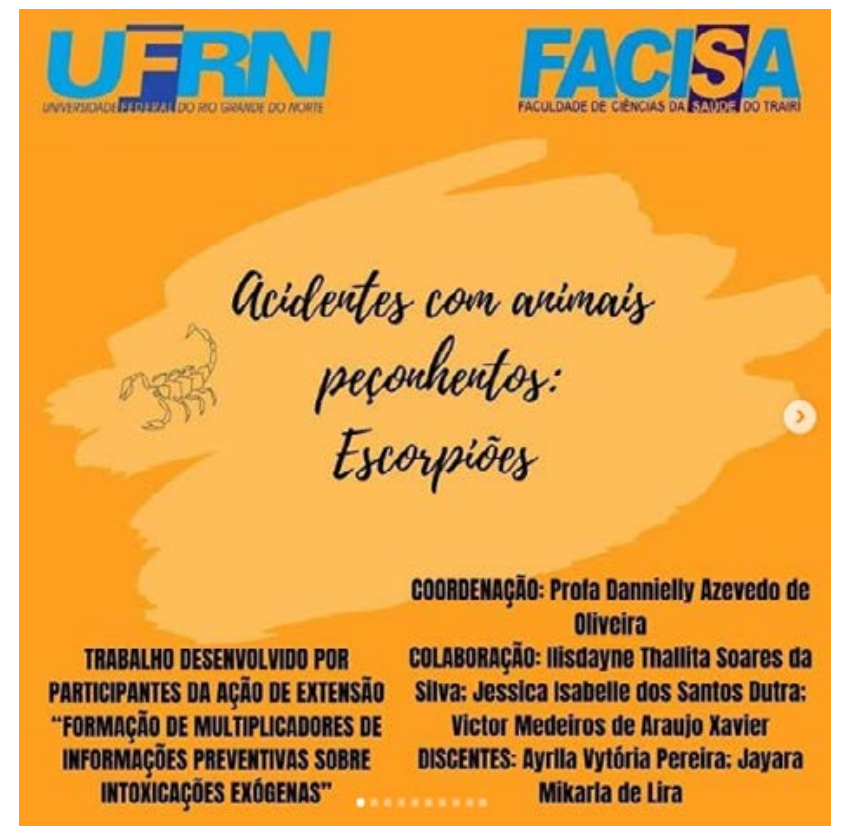

Fonte: Oliveira et al., 2020 . 
Figura 3: Capa do manual sobre os acidentes com domissanitários, vinculada ao projeto "Formação de Multiplicadores de Informações Preventivas sobre Intoxicações Exógenas"

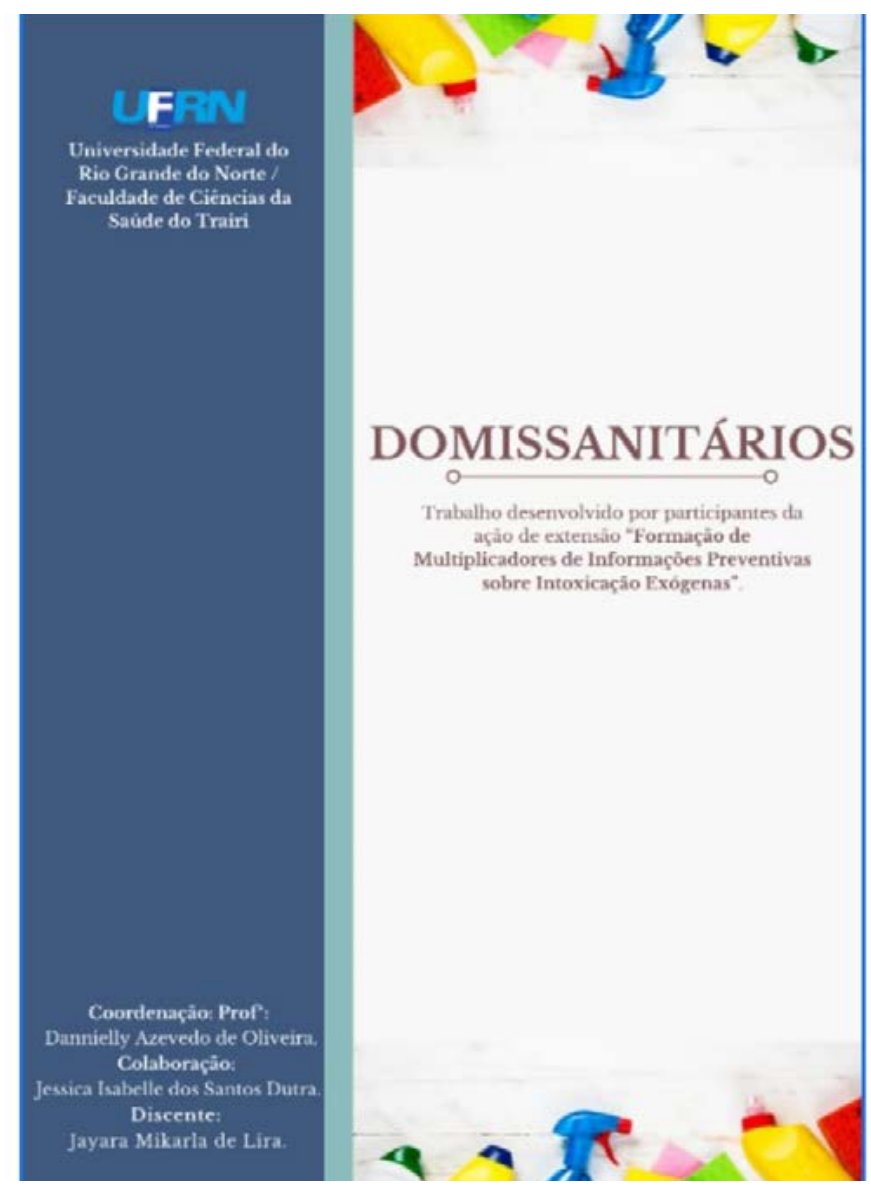

Fonte: Membros do projeto Formação de Multiplicadores de Informações Preventivas sobre Intoxicações Exógenas (2020).

Figura 4: Capa do seminário sobre os acidentes com plantas tóxicas, vinculada ao projeto "Formação de Multiplicadores de Informações Preventivas sobre Intoxicações Exógenas"

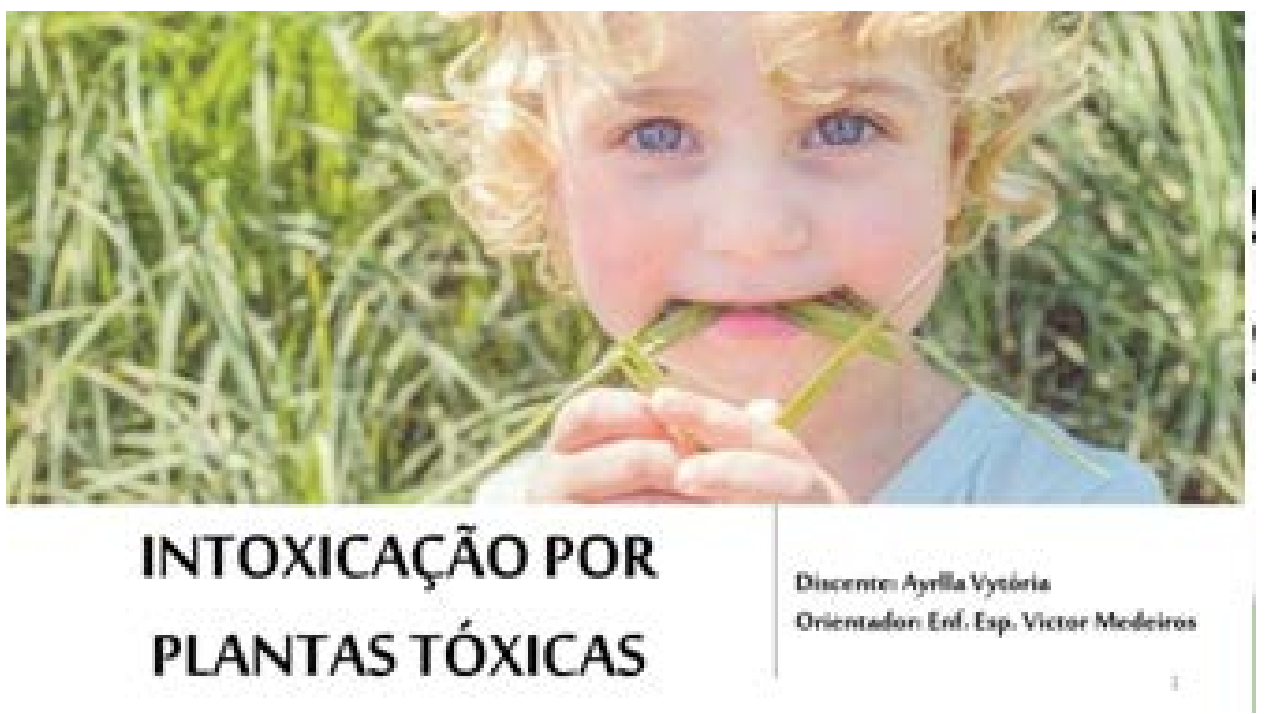

Fonte: Membros do projeto Formação de Multiplicadores de Informações Preventivas sobre Intoxicações Exógenas (2020). 
Figura 5: Capa do seminário sobre os acidentes com intoxicação por fármacos, vinculada ao projeto "Formação de Multiplicadores de Informações Preventivas sobre Intoxicações Exógenas"

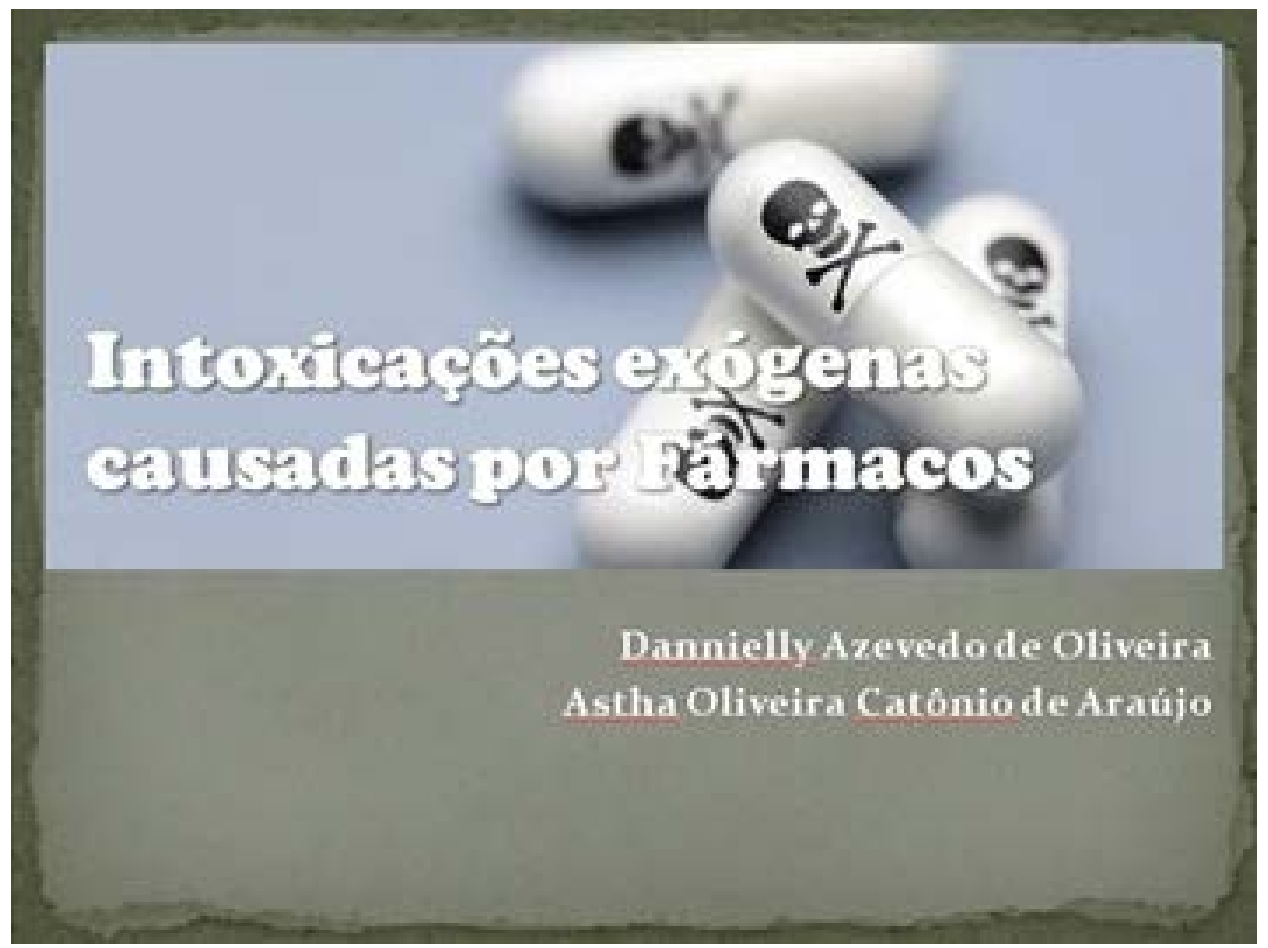

Fonte: Membros do projeto Formação de Multiplicadores de Informações Preventivas sobre Intoxicações Exógenas (2020).

Figura 5: Capa do seminário sobre os acidentes com animais peçonhentos, vinculada ao projeto "Formação de Multiplicadores de Informações Preventivas sobre Intoxicações Exógenas"

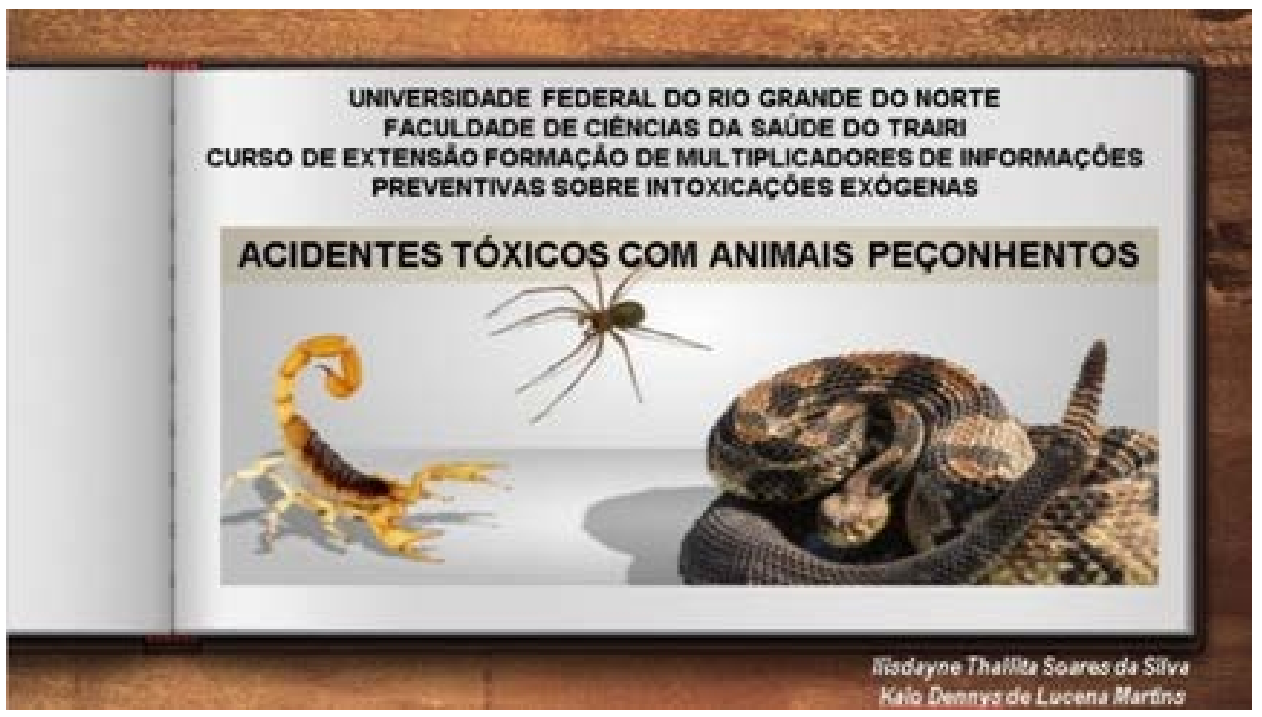

Fonte: Membros do projeto Formação de Multiplicadores de Informações Preventivas sobre Intoxicações Exógenas (2020).

Como resultados indiretos, pode-se citar a aproximação dos integrantes do projeto com o uso diferencial das redes sociais, como o Instagram nos perfis @coronavirusdiariorn e @ufrnfacisa, que são páginas relacionadas à UFRN, instituição a qual o projeto está vinculado, e o ressignificado desses espaços, que podem e devem ser utilizados para disseminar saberes produzidos na universidade, proporcionando 
um retorno à população, visto que a produção desses materiais informativos também funciona como produto de saúde, no que objetiva informar e conscientizar a população sobre cuidados de saúde.

O uso dessas tecnologias digitais contribui para redefinir e transformar a educação, ampliando as vivências da sala de aula, tendo em vista o uso de recursos e ferramentas que criam oportunidades para a aprendizagem e para o trabalho em saúde (FRANZOI, 2OI8). Com a pandemia e o afastamento das salas de aulas, os olhares acadêmicos se voltaram para os potenciais das novas ferramentas que o ambiente virtual poderia permitir para a construção de uma "nova" forma de ensino. Nesse cenário, este projeto de extensão também procurou se reinventar, trazendo novos desafios e oportunidades de aprendizagem.

Existem grandes potencialidades na extensão, sendo essa um dos princípios de mudança do ensino tradicionalista, um ensino que insiste em permanecer, no qual o aluno funciona como um depósito de verdades absolutas e suas experiências são "silenciadas".

Entende-se por extensão o processo de levar a universidade para a comunidade, para alcançar assim o seu comprometimento social. No cenário de tantas limitações encontradas pela universidade, tanto por parte da sociedade quanto do Estado, cabe a ela buscar meios de mudanças, as quais precisam começar de dentro para fora, por meio da comunhão com o ensino, e a pesquisa, para que possa surtir efeitos tanto nos alunos quanto na sociedade (CASTRO, 20O4).

Essas mudanças envolvem também o uso das tecnologias digitais para uma maior aproximação e amplificação das ações extensionistas. Assim, cada vez mais a sociedade torna-se dominante das tecnologias e o ensino universitário precisa acompanhar essas ferramentas para utilizá-las a favor do processo de ensino-aprendizagem e das ações de extensão.

Além disso houve um aprimoramento na intercomunicação e na disciplina pessoal necessária para realização de atividades no formato remoto, contribuindo para uma comunicação assertiva e eficiente, maior empatia entre os integrantes do projeto enquanto viventes de um período frágil, e um autoconhecimento das capacidades e disposições pessoais. É importante entender o trabalho em equipe como uma estratégia, concebida pelo homem, para melhorar a efetividade do trabalho e elevar o grau de satisfação do trabalhador (PIANCASTELLI; FARIA; SILVEIRA, 2005 apud FRANCISCHINI; MOURA; CHINELLATO, 2OO8).

Portanto, torna-se plausível então afirmar que o desenvolvimento dos trabalhos, mesmo que de forma online, possibilitou um crescimento acadêmico para os discentes voluntários do projeto de extensão, seja pela capacitação inicial dos próprios discentes com cursos e pesquisas na literatura científica, e com posterior disseminação desses conteúdos aprendidos através dos materiais produzidos, de modo a retornar para a população o que é produzido academicamente. Como também, no aperfeiçoamento de questões particulares e pessoais, que agregarão aos participantes do projeto, não somente enquanto este continuar em vigềncia, mas por toda a sua jornada acadêmica, fazendo jus aos conceitos prévios que caracterizam uma ação de extensão.

\section{CONSIDERAÇÕES FINAIS}

construção dos materiais educativos permitiu dar continuidade as ações de exA tensão, no sentido de trabalhar para a transformação social, ao mesmo tempo que transforma o estudante, deixando-o mais crítico, participativo e reflexivo, para que se torne empoderado e busque mudanças construtivas e responsáveis para com a sociedade. 
Isso demanda um esforço não de extensão, mas de conscientização, que, se bem realizado, permite aos indivíduos se apropriarem criticamente da posição que ocupam com os demais no mundo.

Nessa perspectiva, foi possível estabelecer uma aproximação maior com as pessoas, mesmo que de forma virtual, sendo relevante para o estabelecimento do compromisso social da universidade, permitindo que os conhecimentos produzidos no ambiente acadêmico sejam aplicados e apreendidos pelos indivíduos na sua vida diária, contribuindo para uma melhora na qualidade de vida e bem-estar da população.

Como limitações apresentadas, destaca-se a qualidade da internet, os equipamentos utilizados durante as reuniões de capacitação, como menor qualidade de imagem e áudio, além da imprevisibilidade do tempo e ambiente externo domiciliar que poderiam influenciar no decorrer das atividades.

\section{REFERÊNCIAS}

BRASIL. Ministério da Saúde. Acidentes por animais peçonhentos: o que fazer e como evitar. [S. 1.], I6 ago. 20I9. Disponível em: http://www.saude.gov.br/saude-de-a-z/acidentes-por-animais-peconhentos. Acesso em: 20 set. $202 \mathrm{O}$.

BRASIL. Sistema Nacional de Informações Tóxico-Farmacológicas. Casos Registrados de Intoxicação Humana por Agente Tóxico e Faixa Etária. 20I7. Disponível em: https://sinitox.icict.fiocruz.br/sites/sinitox.icict.fiocruz.br/files//Brasilz_I. pdf. Acesso em: 20 set. 2020.

BORTOLETTO, M. É.; BOCHNER, R. Impacto dos medicamentos nas intoxicações humanas no Brasil. Cadernos de Saúde Pública, [S.L.], v. I5, n. 4, p. 859-869, out. 1999. FapUNIFESP (SciELO). http://dx.doi.org/Io.I590/soro23IIXI999000400020. Disponível em: https://www.scielo.br/scielo.php?script=sci_arttext\&pid=SoIO2-3ІХІ1999000400020. Acesso em: I9 nov. 2020.

CAMPOS, S.C.; SILVA, C.G.; CAMPANA, P.R.V.; ALMEIDA, V.L. Toxicidade de espécies vegetais. Revista Brasileira de Plantas Medicinais, Campinas, v. I8, n. I, p. 373-382, 20I6. Disponível em: https://www.scielo.br/pdf/rbpm/vionisi/I5i6O572-rbpm-I8-I-SI-O373.pdf. Acesso em: O2 jun. $202 \mathrm{O}$.

CASTRO, L. M. C. A universidade, a extensão universitária e a produção de conhecimentos emancipadores. 2004. Disponível em: http://www.anped.org.br/sites/default/files/resources/CASTRO_Luciana_A_universidade_a_extens_o_e_ produ_o_de_conhecimentos_emancipadores.pdf. Acesso em: I5 set. 2020 .

FRANCISCHINI, A. C.; MOURA, S. D. R. P.; CHINELLATO, M. A importância do trabalho em equipe no programa saúde da família. Investigação, v. 8, n. I-3, 2008.

FRANZOI, M. A. H. Tecnologias digitais da informação e comunicação na graduação em enfermagem: relato de uma atividade pedagógica. Reme, Brasília, v. I22, n. II45, p. I-6, 20I8. Disponível em: http://www.reme.org.br/artigo/detalhes/ı288. Acesso em: 4 jun. 2020.

FREIRE, P. Extensão ou Comunicação? 8. ed. São Paulo: Paz e Terra, I983. 65 p.

GARCIA, R. B; POLISEL, C. G; FRANCK, J. G. Intoxicações Agudas: percepções e práticas de profissionais atuantes em serviços de urgência e emergência hospitalar. Rev. Bras. Farm. Hosp. Serv. Saúde, São Paulo, v. 8, n. 2, p. 32-37, abr./jun. 20I7. Disponível em: http://www.sbrafh.org.br/vi/public/artigos/20I708020500II68BR.pdf. Acesso em: I6 set. 2020. 
HEIDMANN, I. T.s. Buss et al. Promoção à saúde: trajetória histórica de suas concepções. Texto \& Contexto - Enfermagem, [S.L.], v. I5, n. 2, p. 352358, jun. 2006. FapUNIFESP (SciELO). http://dx.doi.org/IO.I590/solo4O7O72O06ooo20002I. Disponível em: https://www.scielo.br/scielo.php?pi$\mathrm{d}=$ SoIO4-O7O7200600O2OOO2I\&script=sci_arttext. Acesso em: I9 nov. 2020 .

JATOBÁ, S. U. S. Urbanização, meio ambiente e vulnerabilidade social. IPEA - Instituto de Pesquisa Econômica Aplicada: boletim regional, urbano e ambiental, 2OII. Disponível em: http://repositorio.ipea.gov.br/bitstream/IIO58/5567/I/ BRU_no5_urbanizacao.pdf. Acesso em: 20 set. 2020.

MONACO, L.M.; MEIRELES, F.C.; ABDULLATIF, M.T.G.V. Animais venenosos: serpentes, anfíbios, aranhas, escorpiões, insetos e lacraias. 2.ed.rev.ampl. - São Paulo: Instituto Butantan, 20I7.

VILAÇA, L; CARDOSO, P. R. Intoxicações na infância: panorama geral do perfil das intoxicações em diferentes países. Rev Med, Minas Gerais, v. 24, n. I, p. 2I-25, 2014. Disponível em: http://rmmg.org/artigo/detalhes/597. Acesso em: I8 set. 2020. 